\title{
Proyecto de nuevo sistema de enseñanza del Derecho en la Facultad de Derecho de la Pontificia Universidad Católica del Perú( ( )
}

Marcial Rubio Correa

\section{Introducción}

Muchas veces un abogado se encuentra con un gerente que conoce mejor que él la legislación aplicable a una actividad empresarial especializada; o con un asistente social que recuerda mejor las reglas sobre familia y menores; o con un contador que sabe casi de memoria cierta ley tributaria. Sin embargo, ninguno de ellos sabe Derecho estrictamente hablando.

Ese mismo abogado puede recurrir también en vía de consejo a uno de sus antiguos profesores quién, aunque pueda no haber pasado

El presente trabajo ha sido básicamente redactado por el Dr. Marcial Rubio Correa, y está corregido respecto de su versión original como consecuencia de su discusión, desarrollo y aportes en la Comisión de Evaluación y Diseño de un Nuevo Plan de Estudios conformada por los Profesores Principales, Srs. Drs. Jorge Avendaño Valdez, quien la presidió, Marcial Rubio Correa, Mario Pasco Cosmópolis, Javier de Belaunde L. de R. y Aníbal Quiroga León; designados por el Decano de la Facultad Dr. Lorenzo Zolezzi Ibárcena en Julio de 1998. Expresa, como escribió su principal autor, "[...] diversas opiniones sobre en qué consistiría el aprendizaje del Derecho y, consecuentemente, sobre la significación que tales consideraciones podrían tener en el Plan de Estudios y en la Metodología del trabajo de enseñanza». Fue presentado a esta Comisión en enero de 1999, la que -en la aludida conformación- trabajó hasta Febrero de 1999, habiendo realizado diversas sesiones de trabajo, entrevistas con los Profesores de las diversas Areas del Departamento Académico de Derecho, y recibido valiosos aportes, sugerencias y críticas. Este aporte, sin duda de notoria avanzada en la enseñanza legal, se publica con la anuencia de su principal autor, del Presidente de la Comisión y del Decano de la Facultad de Derecho en el entendido que su mejor conocimiento, difusión y discusión podrá mejorarlo, lo que podrá facilitar su progresiva adecuación. Asimismo, se le da a conocer como aporte a una nueva visión de la enseñanza legal en nuestro país, consecuentes con la posición de vanguardia que en ello ha tenido, y tiene, nuestra Facultad de Derecho. Nota del Editor General. 
nunca sus ojos por las leyes con las que dicho abogado trabaja normalmente, es una fuente digna de crédito una vez informado de los detalles normativos porque si sabe Derecho.

Una primera constatación consiste en que el abogado debe ponerse al corriente de las normas existentes para poder actuar en el Derecho. Si las conoce de memoria podrá actuar de inmediato y, si no, deberá informarse de ellas. Pero con esto se pone al nivel de los otros. ¿Qué es lo que a partir de una información común con los demás, hace decir que si sabe Derecho?

La primera respuesta, cierta pero parcial, consiste en decir que saber sólo ciertas leyes no es saber Derecho, porque éste incluye muchos otros aspectos que necesariamente deben ser conocidos por un abogado. Por ejemplo, que la legislación sobre una actividad empresarial especializada se halla dentro del Derecho Comercial; que este tiene dimensiones de Derecho Público y de Derecho Privado cada una de las cuales, a su vez, tiene principios distintos. Además, todo el Derecho legislado está sometido a la jerarquía superior de la Constitución, la que debe ser aplicada prácticamente a cada circunstancia.

A lo que el párrafo anterior alude, correctamente, es a la visión sistemática del Derecho: no existen partes dentro del sistema jurídico. El lenguaje tradicional de la teoría se refirió siempre a ramas y esta metáfora recuerda inmediatamente a un árbol, ya que la rama sólo puede ser tal si tiene tronco. En caso contrario, si se separa totalmente, se vuelve una estaca o un palo. La idea de los antiguos fue sistemática y por ello se refirieron a ramas. Los estudiosos contemporáneos prefieren hablar de conjuntos y subconjuntos, lo que no hace sino reforzar la idea de que el Derecho es un sistema.

Pero la diferencia entre el abogado que sí conoce Derecho y el que no lo conoce tanto, así como la diferencia entre el gerente lector de leyes y el abogado, va más allá de la explicación dada hasta aquí. Normalmente, cuando el gerente o el abogado exalumno recurren al que se supone sabe más Derecho que ellos, lo hacen luego de haberse empapado de todos los aspectos normativos (y eventualmente sistemáticos) que conocen. A pesar de haber hecho estos esfuerzos, la situación no queda clara y por eso la consulta.

Puede suceder, por ejemplo, que la posible respuesta a un determinado problema en un área especializada de la actividad empresarial sea la resolución de un contrato, o el pedido de daños, o una queja por 
competencia desleal, o una reclamación administrativa, o una denuncia de naturaleza penal $o$, inclusive, una acción de protección constitucional. A menudo la elección de una de estas vías excluye la posibilidad de utilizar todas o algunas de las otras. ¿Cuál será la mejor para las circunstancias?

El dilema que se presentan en este caso se parece más al del maratonista que inicia la contienda, que al del velocista que está a punto de partir en una carrera de cien metros planos. El primero tiene que encarar la contienda estratégicamente: salir adelante para luego aminorar el paso; hacer lo inverso; determinar de qué competidores no puede alejarse en ninguna circunstancia; saber cual parte del camino le es más fácil y cuál es la más difícil, etc., es decir, tiene que plantearse los diversos problemas, no olvidarse de ninguno y elegir uno o varios cursos de acción. A la inversa, todo lo que el velocista debió pensar (que desde luego es mucho) queda atrás en la posición de partida: una vez llegado allí todo lo que necesita es técnica, fuerza y convicción.

De esta manera, saber Derecho es, también, poder manejar todas las variables de un problema determinado, encontrando sus diversas aristas jurídicas y los cursos de acción posibles para solucionarlo. Aquí aludimos a una habilidad parecida a la que tiene dibujante en las manos: tanto la idea como la capacidad de hacerla realidad son indispensables. Sin ellas, el abogado es menos bueno.

Desde luego, la persona de leyes podrá además escribir sobre su experiencia profesional, analizar y criticar el Derecho existente, elaborar leyes, discutir la naturaleza del Derecho, tomar posición sobre su carácter de ciencia e, inclusive, hacer prospectiva para analizar sus posibles cursos futuros. En criterio de todo ello pueden darse vías iniciales al estudiante de pregrado: algunos, los más capaces, podrán tomarlo de allí. Sin embargo, una formación de este tipo se completará con estudios de postgrado bien diseñados.

Si todo lo dicho antes es cierto, entonces la formación de un abogado de pregrado debe contener lo siguiente: el conocimiento de los elementos normativos esenciales del Derecho (en el sentido que usamos el término, elementos normativos no son sólo disposiciones legislativas); la idea sistemática del Derecho, y la capacidad de plantearse resolver comprehensivamente los problemas jurídicos. 


\section{La taxonomía de Bloom y el aprendizaje del Derecho}

Benjamín Bloom contribuyó a desarrollar la clasificación y jerarquización de las habilidades fundamentales que lleva su nombre. La síntesis es la siguiente:

Los seis niveles fundamentales de la Taxonomía de Bloom

\begin{tabular}{|l|l|}
\hline \multicolumn{1}{|c|}{ Nivel } & \multicolumn{1}{c|}{ Conductas características del estudiante } \\
\hline $\begin{array}{l}\text { Conocimiento } \\
\text { Comprensión }\end{array}$ & $\begin{array}{l}\text { Recordar: memorizar; reconocer; recuperar. } \\
\text { Interpretar; traducir de un medio a otro; describir } \\
\text { con las palabras de uno mismo. }\end{array}$ \\
Análisis & $\begin{array}{l}\text { Resolver problemas; aplicar información para pro- } \\
\text { ducir algún resultado. }\end{array}$ \\
Síntesis & $\begin{array}{l}\text { Subdividir algo para mostrar cómo se reúnen sus } \\
\text { partes; encontrar la estructura subyacente a una co- } \\
\text { municación o mensaje; identificar motivos. }\end{array}$ \\
Evaluación & $\begin{array}{l}\text { Crear un producto único y original ya sea en forma } \\
\text { verbal o como objeto físico. }\end{array}$ \\
& $\begin{array}{l}\text { Tomar decisiones de valor acerca de diferentes asun- } \\
\text { tos; resolver controversias o diferencias de opinión( }\end{array}$ \\
\hline
\end{tabular}

Por las definiciones que utilizamos, preferimos reservar la palabra conocimiento a otro concepto y sustituirla aquí por la palabra información que refleja mejor, en nuestro criterio, lo que se quiere decir con el primer nivel de la taxonomía expresada.

De ella se ha dicho lo siguiente:

1 Orlich, C. Donal Kauchak, Donald P. Harder, Robert J. Pendergrass, R. A. Callahan, Richard C. Keogh Andrew J. Gibson, Harry, Técnicas de Enseñanza. Modernización en el aprendizaje.- México, Editorial Limusa S. A. de C. V., 1994.- p. 124. 
"La taxonomía de Bloom, un trabajo clásico en el área de la enseñanza de las habilidades del pensamiento, fue bautizada con este nombre en honor a Benjamín Bloom, coautor de la taxonomía y un pensador determinante en materia educativa. El hecho de que esta taxonomía haya iniciado su cuarta década como guía de investigación en áreas tan diversas como la investigación de la enseñanza (Woolfolk, 1987), el diseño curricular (Posner y Rudnitsky, 1986), y la investigación sobre la interacción en el aula (Cazden, 1986) es un testimonio de su valor como una herramienta para el análisis de la enseñanza y el aprendizaje en el aula.

En la taxonomía de Bloom se clasifican las conductas cognoscitivas en seis categorías que van desde las más simples hasta las más complejas [...] Al igual que otras taxonomías, la Taxonomía de Bloom es jerárquica, y los aprendizajes de los niveles superiores dependen del conocimiento y las habilidades de los niveles más bajos". ${ }^{2}$

En el plano general del Derecho como sistema, una formación del pregrado debe cubrir necesariamente los tres primeros niveles: conocimiento (en el sentido de información ya señalado), comprensión y aplicación ${ }^{3}$.

En otras palabras, cada curso y cada parte de él, deberían ser analizados en función de sí se está cumpliendo debidamente con estos tres niveles que, como ya se señaló, son sucesivos en el conocimiento humano: sólo se comprende cuando se tiene previamente la información; y sólo se aplica cuando se tiene la información y se la ha comprendido.

Por supuesto que, al aprender, hay ciertas cosas de las que sólo nos informamos: por ejemplo, al leer sobre un tema siempre encontramos bibliografía complementaria de la que tomamos nota sin leerla, por si acaso resulta útil más tarde; al analizar una ley podemos informarnos de que tiene conexión con alguna otra norma extranjera y sólo lo apuntamos por si luego podemos referirnos a ella, etc.

\footnotetext{
Orlich, C. Donald Kauchak, Donald P. Harder, Robert J. Pendergrass, R. A. Callahan, Richard C. Keogh Andrew J. Gibson, Harry.-. Técnicas de Enseñanza. Modernización en el aprendizaje.- México, Editorial Limusa S.A. de C. V., 1994.- p. 123.

Cuando aquí nos referimos al "Derecho como sistema" queremos decir al conjunto del Derecho, no a sus subdivisiones ni al método de trabajo jurídico. El análisis, la síntesis y la evaluación son esenciales trabajando con éstos dos últimos elementos, pero realizar estos procesos de pensamiento con el Derecho como conjunto requiere de una preparación y conocimiento superiores a la que se espera de un egresado del pregrado.
} 
También hay ciertas cosas que sólo debemos comprender pero no aplicar: el abogado que estudia la problemática de la reproducción humana asistida tiene que comprender sus dimensiones biológicas pero no tiene que especializarse en ellas.

En síntesis, de lo que se trata es de que lleguemos al nivel que tenemos que llegar en el aprendizaje (y la enseñanza) de cada unidad de trabajo, sin exceder lo que sea necesario, pero simultáneamente sin escatimar el nivel debido. El tema de los niveles de habilidad debe ser preocupación permanente para el alumno y sobre todo para el profesor al diseñar el curso, al preparar la clase, al dictarla y, por supuesto, al evaluar.

Dentro del Derecho, el conocimiento (en el sentido de información que le hemos dado) puede ser equiparado al conocimiento de la normatividad existente y de los conceptos que le son relativos. Entendemos por normatividad existente tanto las normas positivas (producidas por cualquiera de las fuentes del Derecho) como los principios jurídicos. Aquí está la claridad conceptual y la información actualizada de las disposiciones existentes.

La comprensión, en nuestro criterio, es esencialmente sistemática en el Derecho: cada concepto y cada norma tiene un lugar en el universo jurídico y, sobre todo, los hechos que ocurren en la realidad no tienen lugar predefinido dentro del Derecho sino que tal lugar les es asignado: un cumplimiento de pago puede ser un problema civil, pero también penal, o de ambas naturalezas. Puede concluir en una negociación o en un proceso judicial (entre otras posibilidades). Es la comprensión sistemática la que permite fabricar el problema jurídico dentro del Derecho. Desde luego, muchas circunstancias de la vida son enmarcadas solamente en una de las posibilidades que ofrece el Derecho, pero el buen abogado no debe ser formado para resolver las cosas simples, sino para abordar los problemas complejos, de la misma manera que nadie forma médicos para curar resfríos.

La aplicación consiste en el desarrollo de las habilidades de solución de los problema encontrados mediante el uso de una metodología de trabajo adecuada. Es indispensable y resulta el ámbito del conocimiento donde se juega la verdadera capacidad profesional, de la misma manera que la del médico no se juega en diagnosticar sino en hacer desaparecer el mal. Desde luego, la aplicación de conocimiento dependen de la comprensión y la información ( $\mathrm{y}$ se enriquece en rela- 
ción directa con ellas), pero supone una capacidad adicional generada por el aprendizaje que debe ser buscada como un objetivo específico y no debe ser tomada como un corolario automático.

\section{No se aprende (ni se enseña) una rama, sino Derecho}

Si el objetivo es conocimiento, comprensión y aplicación, y si ello se logra mediante el aprendizaje de partes, de sistema y de habilidades para lograr soluciones, entonces nadie enseña una rama del Derecho. Más bien, enseña el Derecho a través de una rama.

Así, no se es profesor de contratos o de constitucional (ni de tributario o de laboral). El profesor, al buscar el aprendizaje de sus alumnos en estas ramas, las vincula al tronco. Estamos seguros que la inmensa mayoría de los buenos profesores de Derecho que creen que enseñan una rama, si analizan su trabajo verán que enseñan sistemáticamente, sólo que por diversas razones no han sido plenamente conscientes de ello. De lo que se trata es de desarrollar esta conciencia y, más aún, de aplicar la enseñanza del Derecho (y no sólo de una de las ramas) en toda circunstancia: hacer que nuestros planes de estudio, nuestros esquemas de desarrollo de los cursos y en general nuestra praxis de trabajo, lleven a ese resultado final.

\subsection{Los esquemas de asimilación del conocimiento}

Durante la parte final del siglo XIX y todo el siglo XX la didáctica ha sostenido que un ser humano, no importando la etapa de la vida en que esté, aprenderá mejor si antes de abordar un tema específico tiene un esquema general de conocimiento en el que dicho tema se enmarque y, también, que aprenderá mejor si al estudiar aplica simultáneamente el conocimiento que va adquiriendo.

Fueron postulados que aparecieron frente a las concepciones tradicionales según las cuales la repetición y la asociación de ideas, eran las formas de desarrollar el conocimiento.

Como resulta obvio, estas dos concepciones no sólo tienen conseuuencias teóricas. La elección de una u otra determina dos sistemas de aprendizaje y de enseñanza distintos. Sobre todo, cambia el papel del alumno, quien deja de ser un receptor pasivo y se convierte en un constructor activo del conocimiento que aprende. Según las concep- 
ciones contemporáneas reseñadas, el eje de la discusión pedagógica es la pregunta de cómo se aprende. Luego, a la respuesta correspondiente se acomodará el cómo se debe enseñar. En relación a las concepciones tradicionales, esto transforma tanto la función que debe cumplir el profesor, como la mayoría de las cosas que ocurren durante la clase y, en general, durante el desarrollo del curso.

John Dewey fue un autor fundamental, cuya obra se desarrolla entre 1884 y 1948. De él dice Aebli:

«Dewey no se quedó en los enunciados generales acerca de la enseñanza. Su psicología lo condujo a formular reglas didácticas precisas, que se fundamentan en su análisis del acto de pensar. Los rasgos esenciales del método a seguir en la enseñanza, son idénticos a los del acto de reflexión. Se necesita, en primer lugar, "que el alumno se halle en situación de auténtico experimento -que se le empeñe en una actividad continua que le interese por sí misma; en segundo, que un verdadero problema surja en tal situación como estímulo de la reflexión; en tercero, que disponga de información y realice las observaciones necesarias para la solución; en cuarto, que se le aparezcan soluciones provisionales de cuya elaboración ordenada sea responsable; en quinto, que se le dé posibilidad y ocasión de someter sus ideas a la prueba de aplicarlas para determinar su alcance y para que descubra por sí mismo su validez»" ${ }^{4}$.

Esta es una afirmación que se refiere a la manera cómo aprende todo ser humano y, por consiguiente, es aplicable a todas las circunstancias de aprendizaje. De ella también puede apreciarse que los beneficios pedagógicos de la participación activa de quien aprende es un planteamiento conocido ya hace varias décadas.

Piaget, a su vez investigador y conocedor profundo no sólo de la evolución del niño sino de los procesos de aprendizaje humano válidos para todas las edades, enunció principios y elaboró elementos que han tenido una gran influencia en la psicología educativa y en la didáctica de este siglo. Si bien los autores a los que nos hemos referido

4 Hans Aebli.- Una didáctica fundada en la psicología de Jean Piaget.- Buenos Aires, Editorial Kapelusz S. A., 1973.- pp. 40-41. 
previamente demuestran que el aprendizaje activo y la constante reelaboración de conceptos ya se conocían desde tiempo antes, Piaget aporta una sistematización trascendental que puede revisarse con detalle, entre otros, en un trabajo publicado por Fernando Hernández y Juana María Sancho5.

Según ella, la asimilación de conocimientos se abrirá camino dentro de la estructura conceptual que tiene adquirida el sujeto previamente al momento del aprendizaje de que se trata, o no habrá asimilación ${ }^{6}$. La idea que transmite Piaget es que un nuevo conocimiento plantea un desequilibrio en el esquema previo que tiene el sujeto que aprende; el equilibrio debe ser restablecido bien encontrando un lugar al nuevo conocimiento en la estructura preexistente, o bien modificando la estructura misma para abrir un nuevo rubro de conocimiento, debidamente relacionado a todos los demás ya existentes.

Si pensáramos en el Derecho, podríamos poner los siguientes ejemplos de asimilación:

- Una persona que lee la organización de los poderes del Estado dentro de la Constitución peruana, es probable que aprenda ciertos detalles normativos que enriquecen su conocimiento por sobre lo que escuchó en los noticieros o leyó en los periódicos, sin sufrir mayor conflicto cognitivo. Abre un nuevo compartimiento en el índice de sus conocimientos y pone allí lo recientemente adquirido de la lectura de las normas constitucionales.

- Nuestro lector puede leer un manual de Derecho Constitucional y recibir información adicional sobre los poderes del Estado (definiciones, características, descripciones, etc.), que serán integradas dentro de su conocimiento inicial constitucional. Probablemente, el índice mental de la forma como cree conocer ahora el fenómeno constitucional se parezca mucho al índice de la Constitución misma, pero sabrá algo más de cada una de sus partes.

5 Fernando Hernández y Juana María Sancho.- Para enseñar no basta con saber la asignatura. Barcelona, Ediciones Paidós Ibérica S. A., 1994.

Indudablemente, hay una primera etapa del conocimiento que no tiene esquemas previos. Ella corresponde al aprendizaje del infante que se basa en los componentes emocionales, motores y sensoriales. Con ellos elabora sus primeros esquemas de conocimiento. Pero este aspecto no corresponde al tema que abordamos aquí. 
- Nuestro lector lee una obra sobre las distintas formas de gobierno (presidencialista, parlamentarista o mixta) y, entonces, se da cuenta que la Constitución no era la forma de organizar el poder dentro de un Estado sino, en todo caso, una de las posibles variantes de aquellas tres. Así, modificará sus estructuras de conocimiento: comenzará por reconocer que hay formas de gobierno; luego establecerá un escalón inferior con las tres formas señaladas; $y$, finalmente iniciará un tercer rango de conocimiento con las formas constitucionales de cada Estado (el suyo propio incluido), organizadas dentro de los grandes modelos. Habrá hecho una modificación de estructuras conceptuales.

En la psicología del aprendizaje se acepta que ésta es la mejor interpretación de la forma de aprender que tenemos los humanos. Doctrinariamente, su versión didáctica más acabada es el constructivismo que, en lo que atañe a nuestro objeto aquí -que es la enseñanza del Derecho en el pregrado- sostiene los siguientes puntos de vista aprovechables:

«Todo el aprendizaje debe suministrar esquemas de conocimiento, siendo ésta su función principal. Un esquema es una estructura de conocimiento abstracto y genérico almacenado en la memoria que especifica los rasgos o atributos relevantes de un objeto situación o persona. En este sentido, los esquemas son el soporte de la estructura mental.

Las funciones que cumplen los esquemas (guiones y marcos) en la construcción del mundo, son:

a) Proporcionar una estructura de base que permita a la información literal llenar los espacios vacíos de la estructura. Esto facilita la comprensión y reduce el esfuerzo mental cuando se aprende.

b) Dirigir nuestra atención y posibilitar la identificación de lo fundamental y lo secundario.

c) Facilitar la elaboración de inferencias que van más allá de lo literal y lo concreto. Esto lo hacemos como necesidad cognitiva para completar la información y cerrar la comprensión. 
d) Facilitar el almacenamiento de la información a corto y largo plazo.

e) Permitir la elaboración de síntesis conceptuales y ayudar en la reconstrucción del conocimiento.

Hemos señalado que los esquemas ayudan a pasar de la información a corto plazo a la de largo plazo [...] $»^{7}$.

Según el constructivismo, cuyos detalles pueden ser consultados con mayor extensión en la obra referida, didácticamente en el Derecho será más fácil entender el concepto de capacidad si se conoce antes el concepto de persona (del que la capacidad es un atributo), y también será más fácil entender la capacidad de goce y la capacidad de ejercicio si primero se saben los dos conceptos anteriores (porque estos últimos son especies del concepto genérico de capacidad). Desde luego, siempre se enseña el concepto de persona antes que el de capacidad y, recién luego de éste, se enseña las capacidades de goce y de ejercicio. Sin embargo, lo importante es que esta metodología se utilice no sólo para el mejor aprendizaje de cada parte del Derecho, sino también para todo el conjunto.

Es en base a estos postulados sobre cómo se aprende mejor, que consideramos que el plan de estudios de la Facultad debe comenzar con una aproximación general y estructurada a todo el Derecho y, luego, continuar con cursos de especialización que produzcan asimilación por integración y por modificación de estructuras (según el esquema de Piaget). Los seminarios de integración, al final, reforzarán la visión integrada del Derecho una vez que el alumno conozca los detalles que estudió en los cursos de especialización para cada tema y, además, desarrollarán sus habilidades de aplicación.

En este contexto, la organización del plan de estudios por áreas tiene la función de conectar los conocimientos entre sí, de manera que se conforme un esquema inicial interiorizado en cada alumno, que luego se enriquecerá y transformará por su aprendizaje posterior.

Norma Reátegui.- El constructivismo. La dimensión individual y sociocultural.Lima, CEDHUM Centro Psicosocial de Desarrollo Humano, 1995.- p. 17. 


\subsection{Las operaciones del conocimiento}

Aebli dice en referencia a la escuela activa de principios de siglo a la que perteneció Dewey (ya citado antes): «El alumno no debe solamente aprender a utilizar correctamente los instrumentos intelectuales sino que, antes, debe fabricarlos, es decir, adquirir las nociones y las operaciones" $^{8}$.

Y ya refiriéndose directamente a Piaget, el mismo autor señala: «He aquí las operaciones en que las preguntas enunciadas reclaman ejecución: la pregunta ¿qué es? obliga a clasificar el objeto o el fenómeno propuestos; la pregunta ¿es más o es menos? obliga a una comparación para poner en evidencia diferencias y equivalencias; las preguntas ¿dónde? y ¿cuándo? obligan a ordenar en el espacio o en el tiempo alguna cosa; la pregunta ¿por qué? obliga a una explicación; la pregunta ¿para qué? obliga a una evaluación de los fines y de los medios; la pregunta ¿cuánto? obliga a contar, etc. Así, una pregunta o un problema no constituyen sino un proyecto de acción o de operación que el sujeto se apresta a aplicar a un nuevo objeto aún no clasificado, situado en el espacio, contado, etc. Desde luego se comprende también por qué ha podido decirse que una pregunta o un problema contienen un esquema anticipador: bajo forma más o menos esquemática anticipan en efecto la operación a efectuar»".

En otras palabras, para adquirir conocimiento, es preciso adquirir destreza en las operaciones que permiten el desarrollo del aprendizaje. En verdad, los autores de textos de didáctica hacen listas más o menos extensas de ellas, pero aplicadas fundamentalmente al aprendizaje de la escuela primaria y secundaria. La enumeración descriptiva de operaciones de la cita anterior nos hace ver la conveniencia de preguntarnos cuáles son las operaciones que se utilizan en el aprendizaje del Derecho. Si llegáramos a identificarlas, probablemente podríamos basar en ellas nuestra enseñanza.

De lo que se trata es que el alumno desarrolle su habilidad para hacer por si mismo cada una de las operaciones y para identificar las vinculaciones que pueden existir entre una operación y otra. Como veremos a continuación, definir supone clarificar y contrastar. Pero la 
manera correcta de que el alumno aprenda Derecho no consiste en darle una definición clara y distinta, sino en que él pueda definir. Los elementos didácticos para ello son numerosos y diversos (por ejemplo puede presentársele un caso y pedir claridad y distinción; o puede dársele los elementos de un concepto y hacer que él los elabore; o puede dársele diversas definiciones como si fueran fichas de información para que él sintetice su propia definición). Sin embargo, el objetivo pedagógico es claro: si por ejemplo estamos enseñando el concepto de capacidad de ejercicio, es tan importante que el alumno adquiera dicho concepto perteneciente al curso de Derecho Civil I, como que al mismo tiempo desarrolle su capacidad de definir, operación que es universal para todo el Derecho. El profesor deberá tratar de lograr los dos objetivos simultáneamente.

\subsubsection{Las operaciones que en nuestro concepto se desarrollan para co- nocer el Derecho}

Aquí hacemos la enumeración de las operaciones que, entendemos, son propias de la adquisición de información, de la comprensión del Derecho como sistema y de su aplicación, que son los tres niveles de la taxonomía de Bloom que consideramos aplicables al pregrado. Más que agotar el tema, pretendemos iniciar la discusión. Seguramente algunas de las operaciones que aquí reseñamos deberían ser desagregadas y otras reunidas. Lo importante, en última instancia, será tener la lista de las operaciones mentales que el alumno debe manejar para decir que tiene conocimiento del Derecho, y entregárselas a través de toda nuestra enseñanza. Las operaciones mentales que consideramos necesarias en el Derecho son las siguientes:

- Definir conceptos; lo que supone clarificarlos y distinguirlos según la terminología cartesiana.

- Contrastar conceptos e ideas.

- Determinar qué es y que no es norma jurídica.

- Determinar el contenido de las normas jurídicas con precisión.

- Determinar la jerarquía de las normas que aplica.

- Saber relacionar las normas entre sí cuando ello es procedente.

- Interpretar.

- Integrar con aplicación de principios generales y analogías. 
- Comprender y aplicar la relación entre lo sustantivo y lo procesal.

- Discriminar lo relevante y no relevante en los hechos y en el Derecho aplicable a cada caso.

- Describir con precisión tanto los hechos como los problemas, y el Derecho aplicable a ellos.

- Desarrollar su capacidad de enunciar, es decir, de expresar breve, sencilla y correctamente una idea.

- Demostrar las proposiciones que hace.

- Argumentar en el contexto de una discusión.

- Desarrollar su capacidad de elección de problemas y respuestas, sabiendo que en el Derecho los problemas se diseñan y suele haber más de una respuesta posible a ellos.

- Clasificar ideas, normas, problemas, conceptos.

- Concebir la existencia de reglas generales y excepcionales, y saber aplicar dichos conceptos.

- Concebir la existencia de reglas universales y particulares, y saber aplicar dichos conceptos.

- Saber utilizar las categorías de género y especie en toda la conceptualización y en la solución de problemas.

- Desarrollar su capacidad de análisis.

- Desarrollar su capacidad de síntesis.

- Capacitarse en identificar y manejar las relaciones complejas entre el Derecho y la realidad.

Consideramos que un buen abogado realiza constantemente todas estas operaciones. También estamos seguros que los profesores que enseñan materias jurídicas inculcan todas estas operaciones a sus alumnos. De lo que se trata con esta enumeración a propósito de este trabajo es de:

- Determinar si la lista es correcta, si faltan o sobra elementos.

- Evaluar cuánto colabora nuestra enseñanza a formar a nuestros alumnos en estas operaciones.

- Evaluar si al dictar nuestros cursos damos a los alumnos todos los elementos de juicio necesarios para que realicen todas esas operaciones en la materia específica que dictamos, en la medida que todas las operaciones mentales descritas tienden a adaptarse flexiblemente a las diversas ramas según los principios y reglas que cada una de ellas contiene. 


\section{Temas vinculados al trabajo en la clase}

Consideramos que hay cinco aspectos importantes sobre los cuáles vale la pena hacer algunas reflexiones: la preparación del curso, su contenido como una especificación de la preparación, el dictado en clase, la evaluación y el tema de enseñar a aprender.

\subsection{La preparación del curso}

A muchos les parece que un curso existe, es decir, que tiene una temática y una aproximación al aprendizaje predeterminados y que un buen profesor sólo tiene que descubrir cómo es el curso para dictarlo de la mejor manera. Pero ésta es una idea errada: no hay curso. El profesor decide cómo debe ser.

Por supuesto, puede decidir que el curso que dicta sea como el que a él le dictaron. Usualmente, esta es la primera decisión que toma un profesor llamado a enseñar una materia universitaria, porque es la que tiene más a mano. Pronto, sin embargo, van ocurriendo diversas transformaciones que son las que cada profesor, desde su particular punto de vista, introduce en la asignatura: así, la está recreando. Al cabo de cinco años, ya existen diferencias notables en todos los ámbitos: énfasis en ciertos temas, análisis más detallados de ciertas partes, ejemplos mejorados, mayor diversidad en materia de lecturas, preguntas de examen mejor ajustadas a lo que enseña, etc.

Lo importante es que cada profesor inventa su curso y que es bueno tener conciencia de ello aunque nuestra primera decisión sea dictarlo como nos lo dictaron a nosotros mismos, porque las decisiones académicas en esta materia son muy importantes.

Así, por ejemplo, un curso de acto jurídico podrá recorrer los artículos del libro respectivo del Código y ser, de esta manera, de naturaleza exegética. Pero podemos imaginarnos otras maneras de dictarlo. Por ejemplo:

- Concentrar el esfuerzo de aprendizaje en la naturaleza del acto jurídico y su distinción con el negocio jurídico, analizando todas las implicaciones teóricas que hoy tiene el tema. Los demás asuntos (modalidades, vicios de la voluntad, representación, etc.) podrán ser trabajados en base a las normas existentes y a lecturas, con unos 
cuantos casos de práctica. Este es un curso esencialmente teórico con una capacitación profesional adicional.

- Se podrá determinar que los elementos esenciales del acto jurídico son lo que el alumno tiene que conocer con detalle y, así, el curso se centrará en la declaración de voluntad y todos sus elementos, más las causales de nulidad y anulabilidad. El resto podrá verse con referencias genéricas.

- También se podrá pensar que lo más importante del acto jurídico es servir a las otras partes del Derecho Privado porque, en sentido estricto, el acto jurídico sólo es una abstracción conceptual que adquiere corporeidad cuando se enmarca en una declaración unilateral de voluntad, en un contrato, en un testamento, etc. De esta manera, el esfuerzo consistirá en estudiar el acto jurídico en sus vinculaciones con las otras figuras a él referidas en el Derecho privado.

- Finalmente, entre otras posibilidades, podrá pensarse en un curso de acto jurídico que estudie los vínculos de la declaración de voluntad entre el Derecho Privado y el Derecho Público. Se estudiaría, así, cada uno de los elementos de la materia en cada una de las dos grandes ramas para ver sus coincidencias y diferencias.

Además, por supuesto, estas posibilidades podrán ser combinadas en diversas dosis, lo que dará lugar a que aparezcan otras formas de dictar un curso de Acto Jurídico. A partir de aquí podemos ver que el dictado exegético no es la única posibilidad y, en el caso de Acto Jurídico, nuestra opinión es que ni siquiera es la mejor $\left({ }^{10}\right)$.

Creemos que la primera pregunta que nos debemos formular al preparar un curso es ¿qué queremos que aprendan nuestros alumnos? o, de otra manera: ¡cuál debe ser el cambio que se haya operado en ellos cuando aprueben finalmente el curso?

10 Pensamos que si los juristas demoraron mas de milenio y medio, contando a partir de Roma, para identificar al acto jurídico como una categoría particular en el Derecho, tiene que ser un concepto muy abstracto y difícil. Por ello mismo, nos parece que no es razonable pensar que un alumno de Derecho en los primeros ciclos de aprendizaje, pueda aprovechar debidamente este curso. Es mas, pensamos que si no se lo enseña en relación a declaraciones de voluntad de carne y hueso, nunca aprovechara debidamente estos conocimientos. Por ello, consideramos que debería ser estudiado en una visión panorámica del Derecho al inicio de la carrera (;unto con la visión panorámica de los otros cursos), para después estudiar a profundidad, al final de la carrera, toda su significación dentro de la sistemática del Derecho 
Esto condiciona la elección de lo que acabamos de comentar a propósito de Acto Jurídico, pero también otras cosas:

- Si el curso va a ser puramente informativo y de comprensión (no creemos que pueda haber curso puramente informativo en la enseñanza de las profesiones) o si también va a ser de aplicación.

- Si el curso va a tener lecturas y de qué tipo serán éstas.

- Si el método de trabajo en clase será de clase conferencia, activo, o una mezcla de ambas metodologías y cuál será esta combinación en cada una de las partes del curso.

- Si los exámenes consistirán en trabajo de casos o si se deberá responder en base a conceptos. Si podrán ser dados con materiales a mano para consulta o si deberán ser absueltos de memoria.

Es evidente que la determinación de lo que los alumnos deben aprender condiciona muy fuertemente la elección de los temas que acabamos de mencionar, y que dos cursos con finalidades distintas tendrán que tener formas exteriores diferentes. Como el curso no existe sino que se inventa, el profesor siempre hace estas elecciones. Como hemos dicho, de lo que se trata es de que la planifique.

\subsection{Los elementos de contenido del curso}

Al elaborar el plan del curso, puede ser conveniente separar cada uno de los tópicos y determinar qué tipo de tratamiento se le deberá dar. En nuestro criterio las variables que determinarán esta problemática son las siguientes:

- Contenidos éticos del tema.

- Contenidos vinculados a la realidad social.

- Contenidos teóricos, constituidos esencialmente por la bibliografía que deberá trabajarse.

- Legislación aplicable.

- Contenidos provenientes de la aplicación práctica del Derecho: jurisprudencia, costumbres predominantes, fórmulas convencionales, etc.

- Perspectiva histórica, entendida como los antecedentes que conducen a que el tema sea tratado de una manera determinada. 
- La ubicación sistemática del tema dentro del Derecho y de sus diferentes conjuntos.

- Los principios generales sobre la materia.

- La problemática de fuentes del Derecho aplicable.

- La metodología de trabajo del tema, según lo que sea pedagógicamente más conveniente para comprenderlo.

- El razonamiento jurídico que debe utilizarse en el tema, de manera que se cubran aquí todas las operaciones aplicables y que hemos reseñado en el acápite 2.2 de este trabajo.

No todos los elementos antedichos deben figurar en todos los temas del curso, pero será interesante repasarlos para asegurarse de cuándo y con cuáles contenidos deberán ser abordados.

\subsection{El dictado en clase}

También es importante diseñar una estrategia sobre cómo abordar el trabajo en clase. Existen muchas variantes pero las dos básicas son la clase conferencia y la clase activa. La clase conferencia entendida como una exposición del profesor ante los alumnos, interrumpida o no por preguntas. La clase activa como aquella en la que el profesor es un director de debate del trabajo de los alumnos.

Desde luego, dos cosas son importantes: la primera, que cada uno de estos dos tipos de clases admite muchas modalidades que cambian más o menos considerablemente el desarrollo del trabajo dentro de cada tipo genérico; la segunda, que no hay por qué considerar que una excluye a la otra en términos absolutos. En cualquier caso, hay que tener en cuenta que la decisión entre estos modelos no es un asunto de principio sino de eficacia y ésta será distinta en cada tema y circunstancia.

Es muy posible que en un mismo curso haya que hacer clases conferencia y clases activas. Esto podrá ocurrir, inclusive, sobre un tema determinado: primero explicación y luego trabajo práctico. También podrán existir cursos que sólo pueden dictarse mediante conferencias y otros en los que esta modalidad es una pérdida de tiempo. El método debe ser definido en función de los objetivos que se busca cumplir.

\subsubsection{La clase conferencia}


En nuestro criterio, De Juan resume bien las virtudes y deficiencias de este sistema de dictado de clase:

«Las principales ventajas de la clase magistral son:

- Su economía que es, quizá una de sus ventajas más importantes. Dado que nos encontramos en un país no excesivamente rico, este es un aspecto a tener en cuenta. Como pusieron de manifiesto Joice y Weatheral (1957), las clases magistrales consumen 0.05 horas por sesión y por estudiante, supuesto un auditorio de 60, mientras que los grupos de discusión y los de prácticas, emplean 0.33 horas por sesión y estudiante, supuesto un grupo de 12 alumnos. Las clases magistrales son pues un método económico y rápido para proporcionar información a grupos numerosos de estudiantes, con lo que pueden dedicar más tiempo a las clases prácticas.

- Las clases magistrales permiten la transmisión de información tanto fundamental como suplementaria en poco tiempo. Permiten, además, presentar una selección juiciosa y sintética de información procedente de diferentes fuentes: libros de texto, revistas especializadas, ejemplos clínicos, experiencia personal, etc. Se puede también proporcionar información suplementaria a los libros de texto que maneja habitualmente el estudiante, ya éstos quedan a menudo retrasados con respecto al progreso acelerado de la Medicina y las traducciones de textos extranjeros son a menudo incomprensibles, por lo que deben ser controladas. Sin embargo, hay que tener mucho cuidado de no proporcionar al alumno indiscriminadamente los «últimos descubrimientos» que son, a menudo, transitorios.

- Las clases magistrales permiten aclarar conceptos difíciles. En este sentido, es necesario desarrollar la participación activa del alumno en clase, rompiendo la típica pasividad. Se ha de proporcionar a los estudiantes la oportunidad de hacer preguntas sobre temas difíciles en el momento mismo en el que las respuestas tienen una significación especial. Todo esto implica, como decía antes, que la clase teórica se desarrolle en una atmósfera coloquial, que permita preguntas y respuestas. 
- Proporciona seguridad al alumno. El alumno acepta como conocimiento válido y fundado aquello que sus profesores le transmiten en la clase magistral. Por otra parte, este tipo de información es la que se le solicita habitualmente en los exámenes, por lo que cualquier otro tipo de información la ponen en cuarentena."

Los inconvenientes de las clases teóricas, podemos resumirlos en los siguientes puntos:

- "Las clases teóricas mantienen al alumno en situación de pasividad, actuando como meros receptores de los contenidos emitidos por el profesor, lo que va en perjuicio del aprendizaje ya que como veremos más adelante, la actividad facilita la adquisición de conocimientos. Otro problema, en este sentido, es la frecuencia con que los estudiantes faltan a las clases teóricas y usan notas y apuntes tomados por sus compañeros, sin que muchas veces se observe una reducción en su aprendizaje, lo que cuestiona la utilidad de tales clases.

- Por otra parte, la unidireccionalidad de la información y la consiguiente falta de actividad del alumno determina que sea difícil mantener despierta su atención, especialmente si se imparte docencia a un grupo numeroso y en aulas no suficientemente aptas, cosa que ocurre con frecuencia en nuestras universidades.

- Van dirigidas exclusivamente a los objetivos del campo cognoscitivo. Las clases teóricas cumplen un fin informativo, que sobrevalora los objetivos cognoscitivos a costa de los demás objetivos del programa educativo. Incluso dentro de los objetivos del dominio cognoscitivo, la clase magistral no facilita el aprendizaje de objetivos de tercer nivel, es decir, la resolución de problemas.

- Proporciona escasa retroalimentación. Ya que durante una clase teórica la relación profesor alumno es limitada y la información prácticamente camina en una sola dirección. El profe- 
sor no puede darse cuenta de si ésta ha sido captada totalmente por los estudiantes. En este sentido, no respeta el ritmo individual del aprendizaje.

- Su eficiencia depende, en gran medida, de un conjunto de cualidades psicológicas, en cierto grado innatas, del profesor" ${ }^{11}$

Consideramos que la clase conferencia es especialmente útil para los temas en los que la lectura hecha no basta; donde es necesaria la orientación del profesor a través de la elección de alternativas, de la explicación detallada de algunos aspectos y de la presentación de los temas dentro de sus marcos más amplios de referencia.

En todo caso, los aspectos negativos de la clase conferencia pueden siempre ser atenuados por el profesor si prepara su exposición no sólo como una transmisión de conocimientos al alumno, sino como una exposición intercalada con ejercicios que el alumno deba llevar a cabo.

Las exposiciones tienen un esquema de desarrollo. Si los alumnos lo reciben antes de la clase, podrán simplificar grandemente su esfuerzo de tomar notas y de ordenarlas. Ello ayudará a que se fijen en los aspectos centrales y mejorará su atención.

$\mathrm{Al}$ inicio de la clase conferencia se podrá plantear algunos dilemas a los alumnos, que vayan teniendo respuesta con la comprensión de los temas centrales de la disertación del profesor. Esto ayudará a fijar los puntos más importantes en el alumno antes que abandone el aula.

Como puede apreciarse, aun en la clase conferencia es posible utilizar elementos de clase activa para reforzar el aprendizaje.

\subsubsection{La clase activa}

El aprendizaje humano en general (y no sólo el infantil) tiene un apoyo esencial en la acción, es decir, en hacer las cosas que se aprenden. Este proceso es decisivo para la adquisición de conceptos. Aebli, que cumplió el cometido de trasladar a la didáctica aplicada los elementos conceptuales de Piaget, dice respecto de este tema: 
«La aplicación a la didáctica de la psicología de Piaget, debe arrancar de la tesis fundamental según la cual el pensamiento no es un conjunto de términos estáticos, una colección de "contenidos de conciencia», de imágenes, etc., sino un juego de operaciones vivientes y actuantes. Pensar es actuar, trátese de asimilar los datos de la experiencia sometiéndolos a los esquemas de actividad intelectual o de construir nuevas operaciones mediante una reflexión en apariencia "abstracta», es decir, operando interiormente sobre objetos imaginados. La imagen no es el elemento fundamental del pensamiento; constituye más bien su soporte, útil con frecuencia, sin duda, pero no indispensable. Además, en su naturaleza íntima, la propia imagen constituye un acto real y no un residuo de sensación: es una reproducción de los trazos principales de la exploración perceptiva que tuvo lugar durante la percepción de su modelo. De esta tesis puede extraer el didacta una clara visión de los fines intelectuales que la enseñanza debe lograr. Decir que el alumno debe conocer determinadas asignaturas es decir que debe aprender a ejecutar determinadas operaciones. Siempre son las operaciones las que definen a las nociones y es su ejecución lo que debe provocar la enseñanza, efectivamente primero y bajo forma "interiorizada" 0 representativa después". ${ }^{12}$

Si la afirmación de pensar es actuar resulta aplicable a todo conocimiento, lo es más aún al de naturaleza profesional, que consiste en obrar. Hay que tener en cuenta que el supuesto de estas afirmaciones no consiste en que hay que aprender a aplicar para que los conocimientos sirvan, sino en que actuando se conceptúa mejor las cosas.

También es importante notar que, según la psicología contemporánea, el proceso de aprendizaje se refleja en un cambio de conducta, es decir, en que el sujeto que aprende pueda hacer cosas nuevas o diferentes:

De Juan dice:

12 Hans Aebli.- op. cit.- p. 101. 
«Siguiendo a Peterssen (1976) podemos definir el aprendizaje como "modificaciones en la conducta de los individuos, gracias a una serie de experiencias». Por conducta, entiende Peterssen algo perceptible y observable, distinguiendo entre una conducta inicial y una conducta final, dentro del proceso de enseñanza-aprendizaje.

Este paso de una conducta a otra se produce cuando el individuo tiene «experiencias" o, usando la terminología de Skowronek (1970), «interacciones con el ambiente». Sin embargo, como indica este autor, «la conducta observable no es idéntica al aprendizaje...», es entre la conducta inicial y la final cuando se produce el auténtico aprendizaje, o sea, el cambio en las disposiciones de la conducta. No obstante, y desde un punto de vista operativo, resulta más práctico definir el aprendizaje como «modificaciones de la conducta de los individuos debidas a sus interacciones con el ambiente».

Cuando el aprendizaje se refiere a los cambios de conducta que tienen lugar durante la enseńanza, es preferible hablar de "Proceso de enseñanza/aprendizaje». ${ }^{13}$

Por su parte, Gagné, dice:

«El aprendizaje es un cambio en la disposición o capacidad humana, que persiste durante un tiempo y no puede atribuirse simplemente a los procesos de crecimiento biológico. El tipo de cambio denominado aprendizaje se presenta como un cambio en la conducta y sus resultados pueden evaluarse al comparar la nueva conducta con la conducta que se habría presentado antes de que el individuo fuera puesto en una situación de aprendizaje. El cambio puede ser -y de hecho lo es a menudo- una mayor capacidad para cierto tipo de desempeño o actividad. También puede ser una nueva disposición del tipo llamado actitud, valor o interés». ${ }^{14}$

\footnotetext{
13 Joaquín De Juan Herrero.- op. cit. p. 29.

14 Robert Gagné.-. Las condiciones del aprendizaje. México, McGraw-HilI, 1993. pp.
} 
La idea tras estas afirmaciones es consustancial a la formación profesional, que se caracteriza por capacitar a las personas para hacer cosas de su especialidad con calidad. En realidad, estas opiniones apuntan hacia el tercer nivel de aprendizaje de la taxonomía de Bloom, pero suponiendo los dos primeros (información y comprensión).

Es indiscutible que será la clase activa la que permita desarrollar los conocimientos hasta este punto en el alumno. La clase conferencia podrá ser un instrumento utilísimo para la información y la comprensión, pero la enseñanza profesional no debe quedar allí.

Hay muchas maneras de organizar la clase activa. Una forma consiste en que el profesor dicte las clases teóricas y que instructores hagan el trabajo práctico. Esto tiene la ventaja de dar más tiempo de exposición al profesor pero tiene dos grandes desventajas: la primera es que la parte más delicada del aprendizaje que es el tercer nivel de la taxonomía, no es conducido por el profesor más experimentado sino, precisamente, por los instructores que son principiantes en la enseñanza; y, la segunda, que a menos que exista una estrechísima coordinación entre el profesor y sus jefes de práctica, siempre tenderá a existir un divorcio entre la clase teórica y las prácticas. En realidad, el trabajo de coordinar instructores o el de hacer trabajo activo dentro de su clase, son equivalentes para el profesor en lo que a carga se refiere.

¿Puede el profesor desarrollar una clase activa con un número apreciable de alumnos? Sí puede. Desde luego, lo ideal consistirá en que tenga un número máximo de veinte a veinticinco, de tal manera que el trabajo se haga permanentemente con todos ellos participando simultáneamente en lo mismo.

Pero las técnicas modernas de dinámica de grupo permiten establecer pequeños grupos que interactúan con la reunión plenaria. Si el profesor prepara adecuadamente su clase, podrá combinar varias veces en una hora (hora y media continua será mejor aún) la labor de grupos y de pleno. Si el aula tiene facilidad para que las carpetas congreguen a no más de cinco personas en circulo, la participación queda garantizada.

La dinámica de grupo supone que en un grupo de la dimensión indicada en el párrafo anterior, puede dar plena participación a todos sus miembros en la discusión. Si el trabajo se hace siguiendo estrictamente las pautas técnicas existentes, cada grupo deberá tener un direc- 
tor de debates y un relator que luego informa al pleno de los resultados de la discusión del grupo.

Los grupos pueden trabajar los mismos problemas y después comparar sus puntos de vista, o pueden trabajar problemas distintos y encadenarlos o contrastarlos en la discusión total final.

Un aspecto esencial de la clase activa consiste en que el alumno debe haber leído antes de la clase algún material de información y comprensión, y debe haberse enfrentado a problemas que le plantea el profesor para probar sus éxito con los conocimientos que ha pretendido adquirir.

Lo ideal es que el profesor prepare sus propios materiales de lectura elaborando un manual del curso. Con ello se logra que el alumno reciba el mejor mensaje que quiere hacerle llegar el profesor. Si no hay condiciones para escribir el manual, entonces se podrá hacer un volumen de lecturas seleccionadas de otros autores, al que el profesor podrá poner introducciones, explicación de objetivos y problemas a ser resueltos.

Se suele decir que el alumno peruano no lee. Esto es falso. Todo depende de los estímulos que se le den para esa tarea y, también, de los controles de lectura que se establezca. Es verdad que el método activo exige cierto trabajo del profesor para que se garantice que los alumnos lean, pero todo ello redunda en la mejor formación que adquieren. En todo caso, la Facultad siempre podrá proveer formas de ayuda a los profesores para la elaboración y corrección de controles (que para estos propósitos pueden muy bien ser objetivos), colaborando así en el trabajo de los profesores.

La clase activa requiere de la elaboración y trabajo de casos. La idea es que éstos cubran los aspectos esenciales del conocimiento de cada parte del curso, de manera que en la aplicación concreta el alumno pueda no sólo repasar y fijar mejor los grandes conceptos, sino que también aprenda a manejarlos en situaciones concretas, que es como deberá trabajar cuando sea abogado.

Savery y Duffy ${ }^{15}$ han elaborado una lista de siete recomendaciones para el desarrollo de los casos que consideramos útil reproducir aquí:

15 John Savery y Thomas M. Duffy.- «Problem Based Learning: An Instructional Model and its Constructivist Framework». En: VARIOS AUTORES. Constructivist learning environments. Case Studies in Instructional Design.- New Jersey, Educational Technology 
- "Vincular las actividades de aprendizaje a la resolución de problemas o a la realización de actividades amplias".- Esto consiste en que el alumno debe saber que su aprendizaje de ciertas materias siempre está ubicado en un marco de referencia más amplio. Todo ello corresponde al carácter sistemático del Derecho cuyas dimensiones de aprendizaje hemos tratado en el punto 2. de este trabajo. Como puede verse, los casos deben ser una vía para enlazar cada parte del curso con su entorno conceptual. - "Apoyo al alumno para que se apropie intelectualmente del trabajo de aprendizaje que se le ha planteado con el caso".- Hay que mostrar al alumno que no debe estudiar sólo para pasar el examen del curso resolviendo casos similares, sino que el objetivo fundamental es que aprenda a manejar los problemas. Desde luego, si logra este cometido pasará el examen, pero el orden de las cosas tiene que ser éste, no el inverso. Para ello, la motivación al alumno es de primera importancia y un rubro en que el profesor debe poner especial énfasis, sobre todo, haciendo que sus casos sean interesantes de ser trabajados.

- "Elaborar un verdadero caso de trabajo".- Los casos no deben ser artificiales en el sentido de que obviamente no pertenecen a la realidad. Pueden ser casos reales, pero también casos inventados que gozan de verosimilitud, es decir, que pueden ocurrir en la realidad. Desde luego, este tipo de casos refuerza el interés que el alumno tenga en ellos y colabora a lo dicho en el párrafo inmediatamente anterior.

- "Elaborar la tarea y el medio en el cual se desarrolla el proceso de aprendizaje de tal manera que quede reflejada la complejidad del medio en el que el alumno deberá laborar al final de su formación".- Los casos no deben tender a simplificar la realidad. Probablemente debe haber una complejidad incremental a lo largo del proceso de aprendizaje para que se vaya asumiendo progresivamente los diversos elementos involucrados dentro del conocimiento a adquirir. Sin embargo, siempre deberá tenderse a

Publications Englewood Cliffs, 1996.- pp. 135 y ss. (La enumeración que sigue, en la parte que va entrecomillada y en cursiva, ha sido extraída de este texto. La traducción del inglés es nuestra. Con la referencia que hemos hecho, nos excusamos de repetir las citas a la misma fuente). 
que el alumno asimile con los casos toda la complejidad posible hasta que, al final de sus estudios, trabaje prácticamente como un abogado dentro de sus cursos. Una consecuencia de lo dicho es que hay que tender a que el alumno resuelva los casos con todos los elementos de trabajo a mano: libros, leyes, etc. El objetivo debe ser la habilidad para trabajar en el Derecho aunque la memoria puede ser demandada también en cierto grado (sobre todo en materia de conocer lo esencial de los conceptos y de manejo rápido de las fuentes, principalmente las legislativas).

- Dar al alumno la apropiación intelectual del proceso de solución.- El profesor no debe resolver el problema por el alumno. Debe guiarlo, pero tiene que asegurarse de que él desarrolle la habilidad de resolver por sí mismo. La resolución de problemas pasa por preguntarse correctamente por las respuestas posibles. Así, el arte de permitir que otro se apropie intelectualmente del proceso de solución, consiste no en que aprenda a responderse, sino en que aprenda a preguntarse. En otras palabras, el énfasis de esta recomendación está en que el alumno aprenda a aplicar el método de resolución de problemas, más que la forma de responder a ellos. La diferencia es sutil pero trascendental.

- "Diseñar el ambiente de aprendizaje para apoyar y retar a la capacidad intelectual del alumno".- El profesor no debe pensar por el alumno: debe asesorarlo y conducirlo, pero debe permitir que él mismo piense. En este propósito, debe tratar de llevarlo hasta el borde de sus capacidades en el manejo de todas las operaciones y conceptos. Esto puede hacerse así: una vez que el alumno maneja un caso determinado, el profesor puede introducirle complicaciones adicionales que involucren otros conceptos, conflictos entre ellos, o conexiones sistemáticas más amplias dentro del Derecho. De esta manera, estará llevando el pensamiento del alumno hasta los extremos en los que puede desenvolverse. Es por ello que un buen caso, con sus planteamientos adicionales, puede llegar a ser un muy completo equipamiento para comprender una parte de la materia enseñada. Desde luego, exige una preparación especial del profesor para utilizar casos adecuados al grado de conocimiento y a los resultados que se espera de los alumnos en el curso. 
- "Estimular al alumno a probar sus ideas frente a opiniones y contextos alternativos".- Un principio fundamental del método de casos, consiste en que las ideas de cada uno se refuerzan en confrontación con las ideas de los demás. Esto puede realizarse excelentemente en el Derecho. Por lo demás, uno de los principios del aprendizaje consiste en encontrar distintas vías de solución al mismo problema. El Derecho es campo fértil para que este tipo de trabajo pueda ser desarrollado.

- "Dar oportunidad y apoyo al alumno tanto en el contenido del aprendizaje como en el proceso mismo de aprender".- El profesor debe colaborar con sus alumnos tanto en la dirección del proceso de aprendizaje mismo, como en la reflexión sobre la forma cómo se está aprendiendo. Esto último conduce al logro del principio de enseñar a aprender o, desde el punto de vista del alumno, a aprender a aprender.

De esto tratamos con algún mayor detalle en el punto 3.3.5.

No es el caso estudiar aquí con detenimiento ni las clases activas, ni la dinámica de grupo, ni las técnicas detalladas de elaboración de casos, pero todos estos son instrumentos que deben estar permanentemente a la mano, intensamente utilizados tanto con menores como con adultos en el aprendizaje intelectual y, aún, en el emocional. Una reflexión sobre dichos temas permite innovar drásticamente el trabajo dentro del aula, aún con varias decenas de alumnos, permitiendo que todos tengan participación en el trabajo y que, por lo menos, adquieran conciencia de que el curso se juega en la habilidad para resolver problemas.

Un tema muy particular para la enseñanza del Derecho en general, y en especial para el trabajo con método activo es el que nuestro alumno aprenda a manejar los hechos y a plantearse los problemas en ellos involucrados. La clase activa es insuperable para lograrlo.

El abogado suele ser formado para resolver problemas a partir de la normatividad jurídica, pero para identificar los problemas, tiene que ser perspicaz en la determinación de los hechos. En realidad, el trabajo jurídico comienza con la elaboración del qué ocurrió y esto es muy importante porque, normalmente, la persona que recurre a él no tiene idea de cómo procesar los hechos ocurridos.

Desde el punto de vista profesional, los hechos no son un acaecer objetivo frente al cual elaboramos una respuesta. Antes bien, son una 
selección de los elementos que presenta la realidad y que nosotros reconstruimos para crear el fenómeno frente al cual se deberá dar la respuesta del Derecho.

Por ejemplo, para la firma de un contrato poco importará la ropa que llevan los firmantes; pero si hubo un asesinato en una noche de luna llena, será fundamental saber si el vestido utilizado por el agresor permitía que la víctima lo viera a la distancia o, más bien al revés, estaba dispuesto para ocultarse.

Aprender a trabajar con los hechos debe ser tarea esencial del aprendizaje jurídico y el profesor debe facilitar tal ejercicio en todas las disciplinas porque, desde luego, su ameritación varía de especialidad a especialidad.

No se puede hacer un catálogo de todas las sub-operaciones mentales que intervienen en el trabajo de hechos para un abogado, pero lo esencial puede ser lo siguiente:

- Los hechos deben ser ordenados. No existe el orden perfecto, pero tiene que haber uno, cualquiera que sea. En el Derecho es recomendable trabajar cronológicamente, porque las normas jurídicas tienen una aplicabilidad en el tiempo que debe ser siempre analizada. Pero pueden existir otros criterios que, en ciertas circunstancias, sean verdaderamente importantes.

- No todos los hechos tienen el mismo valor. Algunos son relevantes y otros irrelevantes. El ejercicio de discriminar es muy importante.

- No todos los hechos tienen igual grado de certeza: algunos pueden ser fácilmente probados y otros no. La prueba es esencial en el Derecho.

- La percepción de los hechos por las personas es una imagen de la realidad pero no es la realidad: suelen haber versiones distintas y hasta contrapuestas de los hechos por esta causa. Por consiguiente, no hay que dar por hecho comprobable la versión de una sola parte, sobre todo si tiene compromiso emocional con lo ocurrido.

- En el Derecho, los hechos antecedentes y las respuestas que recibieron, pueden ser elementos condicionantes de las respuestas posteriores, siempre que haya analogía entre los hechos previos y los actuales bajo estudio. Conocer las variables determinantes de las analogías es muy importante para discriminar lo que se parece y lo que no se parece. 
El alumno deberá ser entrenado por el profesor en el manejo de estos y otros elementos propios de su disciplina. En esto hay que tener en cuenta que el ejemplo claro y simplificado es muy útil para comprender alguna idea, pero es inútil para desarrollar la habilidad de la aplicación. Por consiguiente, al lado del ejemplo claro y distinto, habrá que hacer practicar al alumno con problemas que le demuestren la complejidad de los elementos conceptuales a considerar.

En cuanto a la determinación de los problemas del caso, es importante notar que en todo asunto interesante hay más de un problema y que todos ellos se hallan interrelacionados entre sí. A menudo para responder a un problema habrá que plantearse otros cuyas respuestas sirven para solucionar al más genérico o comprehensivo. Es muy fácil saber que nadie podrá ser condenado a pena o declarado inocente y libre a menos que se analicen la acción, la antijuridicidad, la imputabilidad, la culpabilidad y la problemática de la pena aplicable. Pero a su vez, para resolver cada uno de estos asuntos, habrá que plantearse otros problemas específicos.

Así, de cada caso se podrá construir un árbol de problemas que consiste en el ordenamiento y relación de ellos entre sí. El buen abogado tendrá que plantearse todos los problemas y ordenarlos entre sí hasta que encuentra las preguntas fundamentales con las cuales se inicia la resolución del caso. Si no trabaja de esta manera, podrá dejar de responder asuntos fundamentales del tema bajo estudio.

No existe el árbol de problemas. Cada especialista elaborará el suyo propio y, a menudo, dos personas distintas harán un ordenamiento muy diferente de los problemas existentes en el mismo caso. Por ello, lo importante no es encontrar la solución correcta al trabajar con problemas sino, más bien, desarrollar el hábito de interconectarlos y jerarquizarlos.

El profesor debería entrenar al alumno en este conjunto de operaciones desde la perspectiva de su propia disciplina, a fin de darle a conocer las particularidades que la distinguen de las otras en este campo.

Finalmente, tanto al analizar conceptos como al trabajar sistemáticamente con ellos, el alumno debe ser capacitado para encontrar todas las posibles y diversas vías de solución, a fin de que contando con el elenco completo, pueda plantear estrategias de resolución 
buscando los aspectos positivos y negativos que cada una de ellas presenta frente a las circunstancias.

Lo más importante consiste en que, casi siempre, es posible encontrar más de una vía de solución a un problema jurídico y que, mientras más complejo es el problema, más soluciones pueden aparecer.

Por consiguiente, la solución no suele ser algo que existe y que debe ser encontrado, sino que es una construcción inteligente de quien aplica el Derecho. Ser creativo en el diseño de soluciones jurídicas es tan importante como saber cuál es el problema jurídico frente al cual nos hallamos.

Las soluciones son muy distintas de ámbito en ámbito del Derecho. Por consiguiente, corresponde al profesor inducir al alumno a explorar estos caminos. No se trata aquí de que desarrolle paralelamente los contenidos esenciales del curso y las soluciones posibles, pero sí de que induzca a su alumno a tener siempre presente el eslabón que vincula la situación a sus posibles soluciones.

En todo caso, como dijimos al inicio, la elección entre el método activo y el de conferencia es un problema técnico en función de los resultados que se espera obtener.

\subsubsection{La metodología de evaluación}

En primer lugar, la evaluación va encadenada a los objetivos del curso. De esto ya hablamos en la primera parte de esta exposición: si el objetivo es que las personas se informen, no se puede tomar un examen de casos y si el objetivo es que se aprenda a resolver situaciones, el examen no puede ser esencialmente memorístico. La combinación de elementos en un examen deberá tomar en cuenta tanto los resultados esperados en el alumno como la manera en que se ha dictado la materia para garantizar que el examen evalúe lo que se debió aprender.

Lo ideal, por tanto, es que el examen haya sido pre-elaborado al inicio del curso y que, durante su dictado, sólo reciba los retoques y reconsideraciones que la experiencia con el grupo de alumnos haga deseable. La preparación del examen con uno o dos días de anterioridad a ser tomado, condiciona a demasiados factores accidentales la elaboración de las preguntas, su calidad y consistencia.

Hace algunos años hicimos un estudio de cómo se calificaba exámenes en toda la Facultad de Derecho de la Pontificia Universidad 
Católica del Perú. Suponiendo que lo esencial de aquel comportamiento supervive aún hoy (y hay muchos indicios para pensar que así es), las principales reflexiones que cabría hacer sobre ellos en nuestra Facultad son las siguientes:

- Una significativa cantidad de exámenes son memorísticos, con lo que sólo atañen a los niveles de información y comprensión. Hay indicios de que para aprobar algunos exámenes en la Facultad basta con estar informado.

- El promedio del rango de calificación de los profesores suele ser de cinco o seis puntos. Así, algunos califican entre 09 y 15; otros entre 15 y 20 ; otros entre 7 y 12. Si bien el número de desaprobados crece en algunas especialidades, en general se mantiene estable y alcanza un promedio del $8 \%$.

- Lo ideal, en nuestro criterio, es utilizar un rango de algo así como quince puntos, entre 05 y 20 . Esto permite una discriminación suficiente en la calidad de los exámenes dados por un grupo de cincuenta o más alumnos. Es importante que la intensidad de trabajo del alumno tenga reflejo en las notas obtenidas porque ello sirve como reto al que trabajó poco y como premio al que se esforzó. No creemos que sea razonable calificar con menos de cinco porque, en ese caso, el alumno se juega el curso prácticamente en un examen. Sin embargo, desde el punto de vista conceptual, nadie puede discutir que se urilice plenamente la escala de 00 a 20.

- Es muy importante que el contenido que el profesor espera de las respuestas, tenga matices suficientes como para discriminar entre la nota mínima y la máxima que se elija. En otras palabras, habrá que tener preguntas que, punto por punto, nos permitan llegar a veinte.

- Creemos que en la enseñanza universitaria también hay que poner veinte y que esta nota debe ir al alumno que, en su grado de conocimiento del Derecho, demuestra saber todo lo que debe esperarse de él.

- Los exámenes no deben ser una ocasión de enfrentamiento entre profesor y alumno. La falta de información sobre cómo será la prueba, las preguntas equívocas o con trampa, la inclusión de preguntas que el alumno no podría responder con sólo haber seguido normalmente el curso, son circunstancias que no deben existir.

- El alumno debe saber con detalle cuáles serán las reglas de juego de 
cada examen, y tener orientación del profesor sobre cómo prepararse para dar bien la prueba. Lo contrario, en nuestro criterio, es desinformar al alumno y, por consiguiente, un trato inequitativo para con él.

- Muchas veces los profesores toman exámenes objetivos para garantizar la facilidad de corrección por el número de alumnos que tienen en clase, y ellos mismos lamentan no tomar exámenes $d e d e-$ sarrollo.

Nosotros creemos que es perfectamente posible combinar las respuestas objetivas y de desarrollo sin recargar excesivamente el trabajo de corrección de la prueba. Para ello hay que recordar que es mucho más difícil expresar una idea en media página que expresarla en página completa: la expresión condensada supone una capacidad intelectual y de comunicación más desarrollada. Pues bien, en un examen objetivo se puede añadir un espacio de cuatro o cinco renglones para que el alumno justifique su respuesta: tendrá que hacerlo en pocas palabras y allí verdaderamente sabremos si sabe elaborar tanto el fondo de sus ideas como la expresión. Estos son exámenes que no toman mucho más tiempo que los objetivos para su corrección. En ellos, la experiencia de saber expresarse se desarrolla significativamente.

Consideramos que a hacer exámenes se aprende toda la vida. Es un ámbito de la enseñanza en el que resulta recomendable que el profesor ensaye nuevas fórmulas permanentemente (por ejemplo, añadiendo preguntas de características nuevas al lado de las clásicas, para ver cómo sirven a la evaluación y, así, permitir la posterior innovación). Si el profesor no innova en materia de evaluación, los alumnos de ciclos superiores transmiten a los de ciclos inferiores las características de sus exámenes y éstos, en definitiva, se vuelven totalmente previsibles en fondo y forma. Si recordamos nuestra época de estudiantes encontraremos numerosas experiencias de profesores a los que se les conocía el truco. Ser predecibles en nuestras evaluaciones es la peor forma de tomar exámenes.

Finalmente, la nota final del curso debe tener, entre sus componentes, notas parciales que evalúan todos los aspectos del aprendizaje del alumno. Así, podrá establecerse controles de lectura, solución de casos prácticos, exposiciones, etc., al lado de los exámenes. Cada una de estas partes, deberá tener una participación en la nota final que sea 
correlativa a su importancia dentro del curso. Informar de esto a los alumnos al principio del semestre de clases, puede ser uno de los indicios más claros del profesor sobre cómo deben estudiar los alumnos.

Lo ideal es que, después de haber dado un examen, el alumno sepa un poco más que cuando entraba a darlo.

\subsubsection{Enseñar a aprender}

Finalmente, y tal vez lo más importante, es que los profesores nos enfrentemos a la responsabilidad que tenemos de enseñar a aprender. El Derecho cambiará muchísimo en los próximos años (como ha cambiado ya en los pasados) y el profesional que formamos ahora deberá enfrentarse a realidades nuevas y complejas que, si no son debidamente comprendidas, lo llevarán a desactualizarse o a especializarse muy estrechamente en cierta disciplina de lo jurídico, lo que le hará perder su calidad de profesional capaz de afrontar los diferentes retos de su disciplina.

Fernando Hernández y Juana María Sancho han intentado una definición interesante (de aprender a aprender. Dicen:

“(...) la definición de aprender a aprender tiene múltiples sentidos. Nisbet y Shucksmith (1987) han recogido los siguientes:

1. «Aprender a aprender supone adquirir las habilidades para hallar información: aprender a obtener información sobre un tema determinado.

2. Aprender a aprender significa dominar los principios generales básicos: aprender las reglas generales que pueden aplicarse a la solución de un amplio conjunto de problemas más particulares. 3. Aprender a aprender se consigue mediante la asimilación de los principios formales de la investigación: equivale a aprender la lógica de las diferentes formas de investigación y los métodos que ha logrado realizar descubrimientos.

4. Aprender a aprender consiste en desarrollar la autonomía en el aprendizaje: en dirigir uno mismo las actividades de aprendizaje. 5. Aprender a aprender es esencialmente una cuestión de actitud o método: implica cultivar una disposición habitual que es intrínsecamente provechosan. 
En cualquiera de estas propuestas se aprecia una combinación de dos necesidades: adquirir métodos propios de trabajo y poder aplicarlos a situaciones de diversa índole y entidad" ${ }^{16}$.

Como resulta obvio, todo ello puede ser aplicado al Derecho, pero no sólo como conjunto sino también a sus diversos ámbitos particulares. Lo que nos anuncia esta cita, desde el punto de vista de contenido, no es muy distinto a lo que hemos reconocido como importante para el diseño de los cursos en el punto 3.2 de este trabajo.

Hay que destacar el párrafo final de la cita, según el cual se reitera que lo fundamental es que el alumno adquiera métodos de trabajo (no sólo conceptos), lo que nos remite nuevamente al tercer nivel de la taxonomía de Bloom. La teoría moderna insiste en que estos dos elementos son importantes no sólo para el presente sino, sobre todo, para el trabajo futuro de nuestro estudiante de hoy, pues él tendrá que vivir aprendiendo.

De estas reflexiones aparece que la calidad de la educación contemporánea consiste en que el profesor pueda disponer la enseñanza de su curso de tal manera que sus alumnos aprendan a aprender para que, luego, puedan estudiar por sí mismos lo que necesiten para el ejercicio de su profesión. El resultado de estas inquietudes, desde luego, deberá ser incorporado a la metodología de desarrollo del curso por quien enseña y ésta es una labor creativa que depende de las habilidades propias de cada profesor y de las características de la materia que dicta.

Pensamos que si nuestra Facultad de Derecho mantiene y desarrolla su ya conocida capacidad de enseñar a aprender, continuará teniendo un lugar destacado en la formación de profesionales de Derecho. Si la pierde, también perderá sustantivamente su actual calidad. Por ello es que el reto consiste en saltar para adelante a la luz de los nuevos desarrollos de la didáctica.

\section{Epílogo}

Por todas las consideraciones hechas en este trabajo, estimamos que es útil revisar el sistema de enseñanza de Derecho que tenemos, en sus 
diversos aspectos y de allí la pertinencia de la discusión a que el Decano ha dedicado a esta Comisión.

Un primer plano es la actualización de los planes de estudios, pero no solamente en lo referente a contenidos, sino en el mejor diseño para garantizar un mejor aprendizaje. Desde este punto de vista, y en la medida que el conocimiento progresa por reestructuración y enriquecimiento de los grandes esquemas mentales de la persona, consideramos que es importante que una primera etapa del aprendizaje del Derecho lo presente como un todo integrado, dando los conceptos esenciales y sus vínculos, aunque en esa primera etapa se sacrifique la profundidad del conocimiento. Diseñar en qué consiste aprender el Derecho como un todo integrado es una labor teórica de mucha envergadura, pero vale la pena intentarlo. Con esta etapa se daría el marco general que sirve para la profundización. Esto serían los tres primeros ciclos de estudios.

Una segunda etapa debería ser la de profundización de los conocimientos adquiridos en el período anterior. Aquí, los profesores no sólo deberíamos preocuparnos de que nuestros alumnos aprendan nuestras materias, sino que deberíamos hacer un permanente esfuerzo de enmarcarla en su contextos más amplios para hacer ver todo tipo de conexiones sistemáticas dentro del Derecho. Estos son los cursos obligatorios que deben llevar los alumnos a partir del cuarto ciclo.

Luego podrá haber una tercera etapa de profundización relativamente libre a través de seminarios y cursos electivos.

Los seminarios de integración, al final de la carrera, deberán servir para profundizar y consolidar los aspectos integrales del Derecho que se impartieron en los tres primeros ciclos y para desarrollar las habilidades de aplicación del Derecho.

Lo importante de este planteamiento consiste en el dar el Derecho integrado desde el principio, a fin de crear en la mente del alumno el soporte sistemático y conceptual dentro del cual pueda poner, como partes interrelacionadas, los conceptos de profundidad. Respecto de lo que aquí decimos es importante rescatar un principio que ha sido tradicional en la Gestalt. Dicen Bigge y Hunt:

"De acuerdo con la ley de carácter de miembro, una sola parte de un todo no tiene características propias, sino que adquiere sus características del contexto en que se presenta. Como lo se- 
ñaló Gardner Murphy, «los partidarios de la Gestalt insisten en que los atributos o los aspectos de las partes componentes, hasta donde pueden ser definidas, quedan explicadas por sus relaciones con el sistema en cuanto a un todo, dentro del cual funcionan». Por ejemplo, una marcha de color en una pintura adquiere su calidad del contexto -los diseños pictóricos que la rodeanmás que de algo inherente a ella misma"17.

Este tema de los conceptos y su contexto merece amplia reflexión en el Derecho, tanto para el ejercicio profesional como para la práctica cotidiana.

En materia de método de trabajo en clase, consideramos que hay que lograr para cada curso, y para cada tema dentro de él, una adecuada combinación de clase conferencia con clase activa. Esto queda a criterio definitivo del profesor del curso. Sin embargo, hay que notar que es responsabilidad de quien se encarga de un curso, determinar qué partes del mismo serán puramente informativas, cuáles otras serán además de comprensión y, finalmente, cuales serán de aplicación. Para esto último, el instrumento de enseñanza es el método activo. Este método exige preparar la clase de una manera bastante distinta a la que se utiliza para la clase conferencia. Es un tema que debe ser abordado y creemos haber tratado los elementos esenciales en este trabajo.

El sistema de calificaciones debe sintonizar con todo lo anterior y la escala de notas que utilice el profesor deberá servir para establecer diferencias en el resultado del mayor o menor rendimiento del alumno. Un rango demasiado estrecho de notas no estimula al que trabaja porque sus notas se parecerán mucho a las de quien no se esfuerza tanto.

Por la rápida transformación de la sociedad y por el avance de los conocimientos, el abogado del mañana tendrá que haber aprendido a aprender si quiere mantener vigencia y calidad a lo largo del tiempo. Las facultades de Derecho que formen a sus alumnos con este criterio entrarán con buen pie al futuro. Las que se conformen con enseñar bien lo de hoy, probablemente perderán preeminencia muy rápidamente.

17 M. L. Bigge y M. P. Hunt.- Bases psicológicas de la educación.- México, Trillas, 1991.- pp. 378-379. 


\section{Fundamentación del cambio de Plan de Estudios}

\section{Aspectos previos}

Varios elementos confluyen para hacer aconsejable un cambio en el plan de estudios de la Facultad de Derecho:

1. El Derecho peruano ha sufrido una gran transformación en esta última década. No sólo han aparecido nuevas leyes, sino que el esquema general de principios también ha sido modificado. Nuestro Derecho ha evolucionado en su esquema general y, con él, han cambiado también las funciones del Estado y el papel que se supone cumplen las personas y las instituciones en la vida social y económica. El tránsito ha sido de un Estado de bienestar e interventor hacia una situación en la que la sociedad civil asume las iniciativas y el Estado controla.

2. La sociedad se ha hecho significativamente más compleja trayendo como una de sus consecuencias, que los intereses de las personas e instituciones sean más individualizados. Este es un fenómeno propio del fin del siglo $\mathrm{XX}$, ayudado por el desarrollo tecnológico reciente. Tiene como impacto en el Derecho, reconocido en la literatura más actual, el dar un carácter más general a la legislación y dejar a la actuación de las personas el diseño completo de las relaciones jurídicas. Todo ello hace necesario que el futuro profesional desarrolle habilidades especiales de planteamiento e identificación de problemas y soluciones en base al caso concreto y no sólo aplicando la ley.

3. La didáctica ha desarrollado concepciones según las cuales la mejor forma de adquirir conocimientos es aquella situación en la que el alumno es el centro del proceso de aprendizaje y el profesor un colaborador en esta tarea. El aprendizaje consiste, en lo fundamental, en que el alumno desarrolle destrezas para el trabajo jurídico. Este punto de vista contrasta con aquel otro según el cual el profesor enseña a un alumno que recibe la información y la incorpora dentro de su caudal de conocimientos. La transformación metodológica que esta aproximación didáctica supone, es muy grande.

4. La psicología educativa considera que el aprendizaje es estructurado, en el sentido de que debe tener grandes esquemas dentro de los 
cuales se insertan los conocimientos de detalle. Es por ello recomendable que la enseñanza parta de un gran marco integrado de conocimientos, para luego profundizar cada uno de los aspectos del Derecho.

5. La propuesta de un nuevo Plan no implica que el actual sea deficiente (por otra parte, es bastante reciente). Pero nuestra Facultad se ha caracterizado siempre por adelantarse en materia de docencia jurídica. El mundo de hoy (y de mañana) presenta nuevos retos al Derecho, que debemos tomar en cuenta. Además, el hecho de que estemos en buen pie en nuestro medio en la enseñanza del Derecho, no quiere decir que debamos renunciar a estar mejor.

La presentación de este proyecto de cambio del plan de estudios, por consiguiente, se fundamenta en las nuevas necesidades de educación legal que aparecen de la realidad tal como es hoy día, y mira para el futuro. Creemos que, en unos años, la educación universitaria de Derecho será bastante parecida a la que aquí proponemos. De lo que se trata es de que nuestra Facultad mantenga el liderazgo en el aporte que ha hecho ya durante varias décadas a la innovación del aprendizaje jurídico. No deseamos que, mañana, siga a otros que desarrollaron primero las ideas que han nacido aquí y de nuestro propio proceso de crecimiento como moderna Facultad de Derecho. Nada de esto, por supuesto, desmerece la calidad del plan de estudios que actualmente existe, ni tampoco sus muy buenos resultados para los alumnos, de los que todos estamos orgullosos.

\section{Las ideas centrales del Proyecto}

Los principales cambios que este proyecto de plan de estudios presenta en relación al actualmente existente son los siguientes:

1. Dedica los tres ciclos iniciales a dar una visión integral del Derecho a los alumnos, de manera que a partir del cuarto semestre profundicen los diversos conocimientos especializados sobre un esquema general ya internalizado. Es de esperar que esto permita al alumno tanto un mejor dominio de todos los conceptos jurídicos y del método de trabajo, como una mejor incorporación posterior de los conocimientos que estudie en los cursos especializados. Concluye 
con seminarios de integración que vuelven a trabajar la visión integral pero con un alumno que ya tiene más conocimientos jurídicos.

2. Trata, con lo dicho en el párrafo anterior, que el alumno tenga permanentemente un "mapa" mental del Derecho. Eso le permitirá, primero, aprender mejor la disciplina y, luego, tener el criterio suficiente para modificar su propia concepción del Derecho en base a una idea general bastante bien formada del mismo.

3. Se pone énfasis en el método activo de enseñanza durante los tres primeros ciclos, con la finalidad de que el alumno tenga mayor posibilidad de aprender, combinando lecturas y trabajo práctico, tanto dentro de clase como fuera de ella. Se busca que tenga una carga de trabajo adicional a las horas de clase de manera que pueda abarcar todo lo que se pretende que aprenda en la primera parte de sus estudios.

4. Dentro de un plan de estudios con esta estructura, se prevé que el alumno pueda revisar varias veces, en distintos niveles de profundidad, los aspectos esenciales del Derecho. Así, reforzará su conocimiento y lo internalizará de mejor manera que si sólo lo estudia una vez en la carrera, como ocurre con el sistema actual de enseñanza.

\section{Intento de síntesis del perfil de nuestro profesional}

En síntesis, el profesional del Derecho del futuro debe estudiar hoy para saber los fundamentos del Derecho y la metodología de identificación y solución de problemas. Debe lograr la posibilidad de entender el Derecho de hoy y del futuro, lo que significa que debe "aprender a aprender". Tiene que saber que el Derecho aplicable que aprende hoy no será el del futuro y prepararse para un ejercicio de los próximos sesenta años. En ello tiene que desarrollar sus capacidades de prevenir problemas jurídicos, no sólo de solucionarlos; debe poner énfasis en el aprendizaje de la sistemática del Derecho y en sus principios de interpretación y aplicación; debe poder interactuar con los especialistas de otras disciplinas del conocimiento y del trabajo en la sociedad, y debe ser un profesional capacitado en las diversas formas de solución de conflictos, sabiendo que ellas encierran diversos "costos de transacción" que son crecientemente importantes para su cliente. 
Por la particular formación que da la Pontificia Universidad Católica del Perú, nuestro profesional deberá desarrollar, además de los aspectos técnicos del conocimiento jurídico, un espíritu ético de trabajo en todos los ámbitos de su especialidad «de acuerdo con las leyes y la moral cristiana", y deberá asumir un compromiso con la solución de los problemas de la sociedad.

No pretendemos formar abogados «especializados» en determinada área, esto es, abogados civilistas, penalistas o constitucionalistas. Como ha ocurrido hasta ahora, el egresado de nuestra Facultad debe tener una formación amplia que le permita desempeñarse en campos diversos, desde la práctica privada hasta el servicio del Estado, pasando por la judicatura, el notariado, el servicio legal en organizaciones no gubernamentales e, inclusive, actividades empresariales, periodísticas, diplomáticas o políticas.

\section{4. ¿Por qué seis áreas?}

Nosotros enseñamos desde hace muchos años el Derecho en aproximadamente diez áreas: civil, procesal civil, penal, procesal penal, constitucional, administrativo, comercial, tributario, laboral y teoría general. Pero ésta no es una clasificación intemporal. En realidad, la mitad de dichas ramas no existían al finalizar el siglo XIX y varias de ellas aún no se dictaban a principios de este siglo. De otro lado, estas "ramas", son en realidad una manera de presentar un sistema complejo de normas y principios que es el Derecho. No son «ramas» paralelas y autónomas entre sí sino que se interconectan y relacionan. Lo que pasa es que ello ocurre en la experiencia profesional, pero no en la enseñanza universitaria. Lo que en verdad ocurre, es que la actual enseñanza universitaria no refleja adecuadamente la realidad y, por tanto, prepara imperfectamente para actuar en ella.

Lo importante en este ámbito de la enseñanza es concebir cómo está actualmente dividida la realidad en relación al Derecho y cómo lo estará previsiblemente en el futuro. Al preparar este plan de estudios hemos considerado que las grandes divisiones son:

- El Derecho Civil, es decir, el ser humano en sus diversas relaciones. Este fue y es el ámbito civil del Derecho, que no corresponde 
sólo al Código Civil como conjunto de temas y normas, sino a la actuación humana, lo que siempre se llamó la dimensión "privada" de la vida jurídica. Esta dimensión debe incluir todas las formas de solución de problemas en las relaciones sociales, una de las cuales es el litigio (de ahí la inclusión de la dimensión procesal en ella), pero también las otras posibles formas de solución de conflictos (que se verán, paralelamente, en un curso de la parte de teoría del Derecho).

- El Estado, que es una entidad que actúa con reglas públicas, tanto constitucionales como administrativas. En realidad, es imposible estudiar la dimensión administrativa del Estado sin conocer el Derecho Constitucional pero, al mismo tiempo, es necesario saber que, salvo pocas excepciones si miramos los números totales, la materialización del Estado de Derecho (y por tanto constitucional), ocurre a través de la actuación administrativa. Por ello consideramos que los constitucional y lo administrativo deben confluir para una adecuada comprensión del Estado aunque, desde luego, reconocemos las diferencias de estas dos ramas tal como están configuradas tanto temática como dogmáticamente.

- La empresa, que es el agente de producción que utiliza crecientemente al Derecho y que crea complejas y numerosas relaciones sociales de todo tipo, muchas de ellas con resonancia jurídica. Es dentro de la empresa (grande y pequeña), que se dan diversos fenómenos interrelacionados: los comerciales, los tributarios y los laborales. Aunque es cierto que cada una de estas ramas tiene su autonomía conceptual y sistemática y que en consecuencia se puede ser especialista en cada una de ellas, también es cierto que un buen abogado tiene que saber los vínculos que existen entre una decisión laboral y sus consecuencias tributarias, y así sucesivamente. Es probable que no tenga que saber todas las respuestas, pero debe estar advertido de las conexiones. Después de todo, hablará con un empresario que tiene interés en que su asesor jurídico trabaje de esa forma.

De otro lado, no hay que dejar de notar que es cada vez mayor el número de abogados que estudia administración o economía bajo diversas formas (cursos de especialización, postgrados, etc.). Esta es una tendencia que se acentuará por la relevancia de la empresa en el mundo actual. Debemos preparar a nuestros alumnos para entender a 
la empresa como conjunto. Así podrán ser mejores profesionales al servicio de ellas y podrán interactuar mejor con los demás profesionales que las integran.

- El área penal, que es tremendamente importante en el contexto general del Derecho y que tiene grandes particularidades por todos conocidas. No hace falta desarrollarlas ante quienes serán lectores de este documento.

- El área procesal, en la cual se estudiará los grandes principios de solución de conflictos a través de la jurisdicción en sus diversas modalidades, y se hará el estudio del proceso en el Perú.

- El área de teoría del Derecho, que tiene valor propio y que también nos releva de la necesidad de mayor descripción.

Consideramos que estas seis áreas serán las que integren de mejor manera los diversos conocimientos y aplicaciones futuros del Derecho en la sociedad y que, por lo tanto, son la concepción que sistemáticamente corresponde mejor para el estudio del Derecho. Estimamos que la clasificación de diez ramas que ha sido tradicional entre nosotros, debe ser superada por la que proponemos.

III. El proyecto de nuevo sistema de enseñanza del Derecho

3.1 Presentación inicial resumen del sistema de enseñanza del derecho

Este proyecto pretende recoger lo bueno de la formación jurídica de la Facultad, e innovar profundamente en las siguientes áreas:

- Sólo puede ser dictado si existe una significativa interacción y colaboración entre los profesores involucrados. En este proyecto no es posible que cada profesor «dicte por su lado".

- Si todo funciona como se debe, en los tres primeros ciclos el alumno debe haber aprendido a manejar los conceptos más importantes del Derecho y la relación que existe entre ellos (habrá leído aproximadamente trescientas páginas por curso, esto es, mil ochocientas por semestre); habrá revisado varias veces las leyes y cuerpos legis- 
lativos fundamentales y habrá aprendido a plantearse y a resolver problemas jurídicos. Más detalladamente, los objetivos en estos tres primeros ciclos son:

a. Que el alumno conozca el "mapa" general del Derecho y pueda identificar sus partes para aplicar correctamente el Derecho.

b. Que sepa y maneje los conceptos fundamentales del Derecho que le permitan entender sus diversas partes y aplicar los aspectos más importantes de las leyes fundamentales.

c. Que conozca las leyes fundamentales que se determine al desarrollar el plan por cada una de las áreas de trabajo.

d. Que esté metodológicamente preparado para tomar un problema jurídico, desarrollar sus principales aristas e indagar las posibles diversas soluciones abiertas por el Derecho.

e. Saber los trámites, documentos y demás elementos de la práctica de los principales aspectos del Derecho.

- Los cursos, a partir del cuarto ciclo, profundizarán los conocimientos de las partes esenciales del Derecho, y contarán con la facilidad de que el alumno ya tiene una idea general del Derecho.

- El trabajo en los tres primeros semestres es el fundamental y está basado en lo siguiente:

a. Que los cursos estén debidamente coordinados en su formulación y que los profesores coordinen durante el dictado. En cada área se establecerán los contenidos mínimos comunes y, por encima de ellos, cada profesor añadirá los propios que considere necesarios.

b. Que se haga una lista de temas esenciales que ningún alumno debe dejar saber y que se haga el texto o los materiales correspondientes para que los estudien por sí mismos. Cada profesor hará materiales propios, de considerarlo necesario, para la parte del curso que él mismo diseña.

c. Que los cursos utilicen intensivamente la metodología activa aunque, desde luego, complementada con otras formas de enseñanza, según el profesor y el área lo estimen conveniente.

d. Que el esfuerzo de los profesores sea presentar, siempre y en cada caso, el todo y las partes del Derecho. 
e. Que se pida paralelamente, pero como exigencia curricular (en la forma que ahora se hace con el idioma extranjero) un grupo de cursos prácticos sobre procedimientos y documentos (saber comprenderlos o redactarlos) que podrían ser dictados por el Centro de Educación Continua y ofrecerse a nuestros alumnos y a terceros, tanto en época lectiva como en vacaciones. Deben ser cursos evaluados y aprobados.

- Es indispensable un compromiso inicial de los profesores que signifique la obligación de:

a. Coordinar entre sí.

b. Preparar anteladamente el curso.

c. No eximirse del dictado cuando les toque.

d. Comprometerse a compartir los descubrimientos de su experiencia en el dictado con los demás.

\subsection{Elementos a tomar en consideración para el contenido de cada curso}

Al elaborar el plan de su curso, el profesor debe plantearse qué tratamiento dará a los puntos siguientes:

- Contenidos éticos del tema.

- Contenidos vinculados a la realidad social.

- Contenidos teóricos constituidos esencialmente por la bibliografía que deberá trabajarse.

- Legislación aplicable.

- Contenidos provenientes de la aplicación práctica del Derecho: jurisprudencia, costumbres predominantes, fórmulas convencionales, etc.

- Perspectiva histórica, entendida como los antecedentes que conducen a que el tema sea tratado de una manera determinada.

- La ubicación sistemática del tema dentro del Derecho y de sus diferentes conjuntos.

- Los principios generales sobre la materia.

- La problemática de fuentes del Derecho aplicable.

- La metodología de trabajo del tema, según lo que sea más conveniente pedagógicamente para comprenderlo. 
- El razonamiento jurídico que debe utilizarse en el tema, que variará según las materias que se trate.

No todos los elementos antedichos deben figurar en todos los temas del curso, pero será interesante repasarlos para asegurarse de cuándo y con cuáles contenidos deberán ser abordados.

\subsection{El plan de estudios}

En el primer acápite presentado a continuación, se hace una introducción a las dimensiones metodológicas que supone este plan de estudios y, a continuación, se presenta la secuencia y peso en créditos de los cursos.

\subsubsection{Las grandes etapas del plan de estudios}

Este plan de estudios tiene tres etapas: los primeros tres ciclos; los ciclos cuarto a sexto, y los ciclos sétimo a noveno.

\subsubsection{Los primeros tres ciclos}

En la concepción de este plan, los primeros tres ciclos son los de formación esencial del alumno en el Derecho. De lo que obtenga aquí dependerá su capacidad profesional futura, principalmente en la comprensión general del Derecho y en su habilidad para el autoaprendizaje.

Se ha previsto pocos cursos por semestre para que la dedicación del alumnos sea concentrada y significativa.

En estos tres primeros ciclos debe tomar los siguientes conocimientos:

- La teoría fundamental del Derecho. Aún cuando metodológicamente se va a trabajar con método activo y con uso intensivo de casos y normas, se espera que cada alumno lea por lo menos trescientas páginas por curso, lo que da un total de más de cinco mil páginas estudiadas para los tres ciclos, teniendo en cuenta que se prevé seis cursos por ciclo.

- La habilidad metodológica de "saber cuál es el problema y dónde hay que buscar la respuesta”. 
- Manejarse con facilidad en las normas fundamentales: la Constitución, los grandes códigos y las leyes más importantes, entendiendo por todos ellos los que permiten darse una idea general del Derecho positivo.

En estos tres ciclos la enseñanza es totalmente distinta a la que hemos hecho hasta ahora. Los rasgos principales que marcan estas diferencias son:

- El alumno no estudia "especializadamente» partes del Derecho, sino que las estudia necesariamente de manera integrada. El profesor tiene que esforzarse por dar la imagen general del Derecho que enseña, y las relaciones entre sus partes y conceptos, y no debe poner el énfasis en profundizar.

- En la actualidad tratamos de dar al alumno, en cada curso, tanto la visión de la parcela que corresponde a nuestro curso, como toda la profundidad posible del mismo. La idea de estos tres primeros ciclos es que el profesor sacrifique profundidad en virtud de dar la idea general del Derecho.

- La metodología activa es esencial. También los casos y los materiales de enseñanza. Los cursos, más que con exámenes, deben ser calificados con prácticas periódicas que garanticen una evaluación permanente.

- La preparación antelada de los cursos, y la coordinación de esfuerzos entre los profesores de cada ciclo y de cada tipo de materia es esencial.

- Utilizando cifras arbitrarias que sólo permiten dibujar ideas, consideramos que el éxito de estos tres primeros ciclos sólo queda asegurado si el alumno pone dos tercios del esfuerzo fuera de clase y un tercio dentro de ella. Es decir, que dos de cada tres horas de su trabajo en el plan de estudios las hace en su casa, y ello de manera sostenida a lo largo de los tres semestres y en cada curso.

\subsubsection{Los ciclos cuarto al sexto}

Estos ciclos tienen parecido a los primeros seis ciclos del plan de estudios actual, pero es un parecido formal, no sustantivo. Hay que tener en cuenta que, para la mayoría de los cursos de esta parte en el nuevo plan de estudios propuesto, el estudiante ya ha visto las normas 
aplicables, ha leído fundamentos y ha trabajado casos. Por consiguiente, los cursos de los ciclos cuarto a sexto son, estrictamente hablando, cursos de profundización.

Estos cursos pueden ser magistrales o con método activo. La decisión correspondiente se tomará en cada caso.

\subsubsection{Los ciclos sétimo a noveno}

Son ciclos de especialización con cursos electivos, y de capacitación en el trabajo con grandes casos jurídicos en los seminarios de integración.

Los cursos electivos son de dos tipos: los que se dictan actualmente como tales, y los obligatorios del plan de estudios vigente que dejan de serlo en el nuevo que se propone. Los profesores deberán ser advertidos que los alumnos vienen con un bagaje de estudios bastante distinto al acostumbrado y que, probablemente, requerirán a sus profesores un trabajo metodológicamente más afinado.

\section{IV.El plan de estudios propuesto}

\section{CICLO I}

Derecho Penal I

créditos

Derecho Civil I

3

Introducción a las Ciencias Jurídicas

Bases Romanistas del Derecho Civil

Constitucional y Administrativo I

Teoría del Proceso: conflictos y soluciones

CICLO II

Destrezas Jurídicas

Penal y Procesal Penal II 3

Derecho Civil II 3

Derecho de la Empresa I 3

Personas Jurídicas 3

Constitucional y Administrativo II 3 


\section{CICLO III}

Penal y Procesal Penal III 3

Procesal Civil I $\quad 3$

Derecho de la Empresa II 3

Metodología de la investigación jurídica 3

Derecho Internacional Público 3

Sociología del Derecho 3

CICLO IV

Derecho Penal IV 3

Contratos 3

Procesal Civil II

Contabilidad 3

Teología 3

Constitucional 3

Acto Jurídico

CICLO V

Derechos Reales

Sociedades $\quad 4$

Tributario 4

Laboral 3

Filosofía del Derecho 3

Derecho de Familia 3

CICLO VI

Sucesiones 4

Obligaciones $\quad 3$

Deontología forense 3

Cursos electivos 9

CICLO VII

$\begin{array}{ll}\text { Cursos electivos } & 18\end{array}$ 
CICLO VIII

Metodología de investigación de tesis 3

Seminario de integración 3

$\begin{array}{lr}\text { Cursos electivos } & 12\end{array}$

CICLO IX

Seminario de integración 3

Seminario de integración 3

$\begin{array}{ll}\text { Cursos electivos } & 12\end{array}$

\section{ANEXO I}

Lista de cursos electivos que se ofrecería.

\section{DERECHO ADMINISTRATIVO}

Derecho administrativo 2

Temas de Derecho administrativo.

Derecho regional.

Derecho municipal.

DERECHO CIVIL

Derecho internacional privado

Garantías.

Contratos típicos I.

Contratos típicos II.

Taller de Derecho civil y Derecho procesal civil

Responsabilidad civil

Temas de Derecho civil

Seminario de propiedad

Derecho del menor

Temas de Derecho civil patrimonial.

DERECHO CONSTITUCIONAL

Derecho constitucional comparado 
Garantías constitucionales

Derechos humanos

Poder Ejecutivo

Temas de Derecho constitucional

Ciencia política

Derecho parlamentario.

\section{DERECHO INTERNACIONAL}

Arbitraje comercial nacional e internacional

Temas de Derecho internacional público

Derecho del mar y otros espacios

Sujetos de Derecho internacional

Solución de controversias internacionales

Derecho del comercio internacional

Transacciones internacionales

Derecho de la integración

Introducción al Derecho internacional económico

Derecho de los tratados

Temas de Derecho internacional privado

Relaciones internacionales

\section{DERECHO LABORAL}

Seguridad social

Régimen laboral de los trabajadores estatales

Temas de Derecho individual del trabajo

Temas de Derecho colectivo del trabajo

Temas de teoría general del Derecho laboral

\section{DERECHO MERCANTIL}

Títulos valores

Propiedad industrial.

Transporte

Concursal 
Seguros

Aeronáutico

Bancario

Derecho e la competencia

Derechos de autor

Temas de Derecho mercantil

\section{DERECHO PENAL}

Derecho penal III

Medicina legal

Derecho penal económico

Criminología

Derecho de ejecución penal

Temas de Derecho penal

Teoría de la sanción penal

\section{DERECHO PROCESAL}

Derecho procesal del trabajo

Derecho procesal civil III

Derecho procesal civil especial

Derecho procesal penal especial

Derecho judicial

Temas de Derecho procesal

\section{DERECHO TRIBUTARIO}

Impuesto a la renta

Temas de Derecho tributario

Tributación municipal y regional

Impuestos patrimoniales

Derecho aduanero

Impuesto al consumo

ECONOMIA

Economía 
Instituciones financieras

Desarrollo económico

Análisis económico del Derecho

Política fiscal

\section{TEORIA GENERAL DEL DERECHO}

Historia del Derecho peruano

Derecho y desarrollo

Derecho comparado

Derecho Romano

Antropología jurídica

Seminario de investigación 1

Temas de teoría general del Derecho.

\section{VARIOS}

Derecho de minería y energía

Gestión empresarial

Derecho cooperativo

Derecho agrario

Seminario mujer y Derecho

Derecho registral y notarial

Negociación y conciliación

Informática jurídica

Derecho del medio ambiente

Derecho urbanístico

Proyección social

Seminario especial

Derecho eclesiástico

\section{ANEXO II}

Seminarios de Integración

1. Seminario de integración en Derecho administrativo.

2. Seminario de integración en Derecho civil y procesal civil I. 
3. Seminario de integración en Derecho civil y procesal civil II.

4. Seminario de integración en Derecho constitucional.

5. Seminario de integración en Derecho internacional.

6. Seminario de integración en Derecho laboral.

7. Seminario de integración en Derecho mercantil.

8. Seminario de integración en Derecho penal y Derecho procesal penal.

9. Seminario de integración en Derecho tributario.

10.Seminario de integración en teoría general del Derecho. 